\title{
A New Diversity Guided Particle Swarm Optimization with Mutation
}

\author{
Radha Thangaraj ${ }^{1}$, Millie Pant ${ }^{1}$ and Ajith Abraham ${ }^{2}$ \\ ${ }^{1}$ Indian Institute of Technology Roorkee, India \\ ${ }^{2}$ Norwegian University of Science and Technology, Norway \\ t.radha@ieee.org,millifpt@iitr.ernet.in, ajith.abraham@ieee.org
}

\begin{abstract}
This paper presents a new diversity guided Particle Swarm Optimization algorithm (PSO) named Beta Mutation PSO or BMPSO for solving global optimization problems. The BMPSO algorithm makes use of an evolutionary programming based mutation operator to maintain the level of diversity in the swarm population, thereby maintaining a good balance between the exploration and exploitation phenomena and preventing premature convergence. Beta distribution is used to perform the mutation in the proposed BMPSO algorithm. The performance of the BMPSO algorithm is investigated on a set of ten standard benchmark problems and the results are compared with the original PSO algorithm. The numerical results show that the proposed algorithm outperforms the basic PSO algorithm in all the test cases taken in this study.
\end{abstract}

Keywords-Particle Swarm Optimization; Diversity; Mutation; global optimization.

\section{INTRODUCTION}

The concept of Particle Swarm Optimization (PSO) was first suggested by Kennedy and Eberhart [1]. Since its development is 1995, PSO has become one of the most promising optimizing techniques for solving global optimization problems. It has been shown empirically in many studies to work well, outperforming other optimization techniques such as evolutionary algorithms. Although the rate of convergence of PSO is good due to fast information flow among the solution vectors, its diversity decreases very quickly in the successive iterations resulting in a suboptimal solution. One of the simplest methods to overcome the problem of diversity loss is to capitalize the strengths of EA and PSO together in an algorithm. A variety of methods combining the aspects of EA and PSO are available in literature [2] - [7] etc. Out of the EA operators, mutation is the most widely used EA tool applied in PSO [8], [9]. The concept of mutation is quite common to Evolutionary Programming (EP), Genetic Algorithms and Differential Evolution. Mutation has been introduced into the PSO as a mechanism to increase the diversity of PSO, and by doing so improving the exploration abilities of the algorithm. Mutation can be applied to different elements of a particle swarm. The effect of mutation depends on which elements of the swarm are mutated. If only the neighbourhood best position vectors are mutated, then effect is minimal, compared to mutation of particle position vectors. Velocity vector mutation is equivalent to particle's position vector mutation, under the condition that the same mutation operator is considered [10].
There are several instances in PSO where mutation is introduced in the swarm. Some mutation operators that have been applied to mutate the position vector in PSO include Gaussian Mutation [11] - [15], Cauchy [15], [16], Chaos mutation [17] - [19] etc. However, in our knowledge none of the above mentioned techniques uses diversity as a measure to guide the swarm. This paper presents a new PSO algorithm based on EP Mutation with the help of Beta distribution; also it uses a diversity enhancing mechanism to improve the performance of the swarm. The proposed Beta Mutation PSO algorithm is named as BMPSO. The BMPSO algorithm uses diversity threshold values $d_{\text {low }}$ and $d_{\text {high }}$ to guide the movement of the swarm. The threshold values are predefined by the user.

The rest of the paper is organized as follows: Section II describes the original Particle Swarm Optimization algorithm. In section III, the proposed BMPSO algorithm is discussed; section IV deals with the results and discussion. Finally, this paper concludes with section V.

\section{PARTICLE SWARM OPTIMIZATION}

PSO is a multi-agent parallel search technique developed by Eberhart and Kennedy in 1995, inspired by social behavior of bird flocking or fish schooling. The particles or members of the swarm fly through a multidimensional search space looking for a potential solution. Each particle adjusts its position in the search space from time to time according to the flying experience of its own and of its neighbors (or colleagues).

For a D-dimensional search space, the position of the $i^{\text {th }}$ particle is represented as $X_{i}=\left(x_{i 1}, x_{i 2}, \ldots, x_{i d}, \ldots, x_{i D}\right)$. Each particle maintains a memory of its previous best position $P_{i}=\left(p_{i 1}, p_{i 2}, \ldots, p_{i d}, \ldots, p_{i D}\right)$. The best one among all the particles in the population is represented as $P_{g}=\left(p_{g 1}, p_{g 2}, \ldots, p_{g d}, \ldots, p_{g D}\right)$. The velocity of each particle is represented as $V_{i}=\left(v_{i 1}, v_{i 2}, \ldots, v_{i d}, \ldots, v_{i D}\right)$.

During each generation each particle is accelerated toward the particles previous best position and the global best position. At each iteration a new velocity value for each particle is calculated based on its current velocity, the distance from the global best position. The new velocity value is then used to calculate the next position of the particle in the search space. This process is then iterated a number of times or until a minimum error is achieved. The two basic equations which govern the working of PSO are that of velocity vector and position vector given by: 
$v_{i d}=\omega^{*} v_{i d}+c_{1} r_{1}\left(p_{i d}-x_{i d}\right)+c_{2} r_{2}\left(p_{g d}-x_{i d}\right)$

$x_{i d}=x_{i d}+v_{i d}$

Here $\omega$ is inertia weight, predefined by the user. $c_{1}$ and $c_{2}$ are acceleration constants. They represent the weighting of the stochastic acceleration terms that pull each particle toward personal best and global best positions. Therefore, adjustment of these constants changes the amount of tension in the system. Low value of these constants allow particles to roam far from the target regions before tugged back, while high values result in abrupt movement toward, or past, target regions [20]. The constants $r_{1}, r_{2}$ are the uniformly generated random numbers in the range of $[0,1]$. The first part of equation (1) represents the inertia of the previous velocity, the second part tells us about the personal thinking of the particle and the third part represents the cooperation among particles and is therefore named as the social component [21].

\section{Proposed BMPSO ALgORITHM}

The Beta Mutation Particle Swarm Optimization is simple and modified version of Particle Swarm Optimization algorithm; it uses Beta distribution to mutate the particle. The BMPSO algorithm has two phases namely attraction phase and mutation phase. The attraction phase is same as that of the classical PSO, while in the mutation phase the swarm particles position vectors are mutated using Beta Distributed Mutation (BDM) operator. The BDM operator is $\mathrm{EP}$ based mutation operator and is defined as:

$$
\begin{gathered}
x_{i}^{t+1}=x_{i}{ }^{t}+\sigma_{i}^{\prime}{ }^{*} \text { Betarand }_{j}() \\
\text { where, } \sigma_{i}^{\prime}=\sigma_{i}{ }^{*} \exp \left(\tau N(0,1)+\tau^{\prime} N_{j}(0,1)\right)
\end{gathered}
$$

$N(0,1)$ denotes a normally distributed random number with mean zero and standard deviation one. $N_{j}(0,1)$ indicates that a different random number is generated for each value of j. $\tau$ and $\tau^{\prime}$ are set as $1 / \sqrt{2 n}$ and $1 / \sqrt{2 \sqrt{n}}$ respectively. Betarand $_{j}$ () is a random number generated by beta distribution with parameters less than 1 .

The BMPSO starts like the classical PSO i.e. it uses attraction phase (Eqn. (1)) for updating velocity vector and uses (2) for updating position vector. In this phase, the swarm contracts rapidly due to the fast information flow among the particles, as a result, the diversity also decreases consequently the chances of the swarm particles to get trapped in some local region or some suboptimal solution also increases. In BMPSO algorithm, we keep a check on the decreasing value of diversity with the help of a user-defined parameter called $\mathrm{d}_{\text {low }}$. When the diversity of population drops below, $d_{\text {low }}$, it switches over to the mutation phase, with the hope of increasing the diversity of the swarm population and thereby helping the swarm to escape the possible local regions. This process is repeated until a maximum number iteration is reached or the stopping criterion is reached.

The Beta distribution used in this study has the probability density function,
$f(x)=\frac{1}{B(\alpha, \beta)} x^{\alpha-1}(1-x)^{\beta-1}, \alpha>0, \beta>0$

with parameters less than 1 .

\begin{tabular}{|c|c|c|}
\hline \multirow{2}{*}{$\begin{array}{l}\text { Step } \\
\text { Step }\end{array}$} & 1 & tialize \\
\hline & 2 & $\begin{array}{l}\text { Initialize the positions and } \\
\text { velocities of all particles } \\
\text { using uniformly distributed } \\
\text { random numbers }\end{array}$ \\
\hline tep & 3 & $\begin{array}{l}\text { Evaluate the objective function } \\
\text { values of all particles in the } \\
\text { swarm }\end{array}$ \\
\hline tep & 4 & 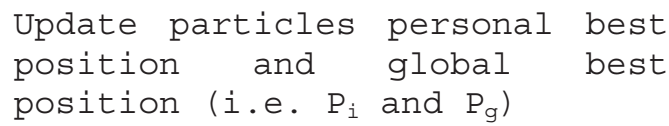 \\
\hline tep & 5 & $\begin{array}{l}\text { Calculate the diversity } \\
\text { swarm }\end{array}$ \\
\hline \multirow[t]{5}{*}{ Step } & 6 & $\begin{array}{l}\left.\text { If (diversity }<d_{10 w}\right) \\
\text { Update particles } \\
\text { using Eqn. ( } 3 \text { ) }\end{array}$ \\
\hline & & Else \\
\hline & & $\begin{array}{lll}\text { Update } & \text { particles } & \text { velocity } \\
\text { and } & \text { position } & \text { vectors }\end{array}$ \\
\hline & & $\begin{array}{l}\text { according to equations (1) } \\
\text { and (2) respectively }\end{array}$ \\
\hline & & End if \\
\hline tep & 7 & $\begin{array}{l}\text { Evaluate } \\
\text { values }\end{array}$ \\
\hline & 8 & Update $P_{i}$ and $P_{g}$ \\
\hline ep & 9 & $\begin{array}{l}\text { If (Stopping criteria } \\
\text { reached) then go to step } 10 \\
\text { Else go to step } 5\end{array}$ \\
\hline te & 10 & $\begin{array}{l}\text { Print the global best particle } \\
\text { and the corresponding fitness } \\
\text { function value }\end{array}$ \\
\hline
\end{tabular}

The computational steps of BMPSO are given below:

\section{EXOERIMENTAL SETTINGS AND NuMERICAL RESUlTS}

For comparison of PSO and BMPSO algorithms, a collection of 10 standard benchmark problems with box constraints is considered. Mathematical models of the problems along with the true optimum value are given in Table I. The entire set of test problems taken for the present study is scalable i.e. the problems can be tested for any number of variables. However, for the present study we have tested the problems for dimensions 10,30 and 50 .

In order to make a fair comparison of basic PSO and the proposed BMPSO algorithm, we fixed the same seed for random number generation so that the initial population is same for both the algorithms. The population size is taken as 20 for all the test problems. A linearly decreasing inertia weight is used which starts at 0.9 and ends at 0.4 , with the user defined parameters $\mathrm{c}_{1}=2.0$ and $\mathrm{c}_{2}=2.0$. For each algorithm, the maximum number of generations is set as 1000,2000 and 3000 generations for dimensions 10, 30 and 50 respectively. . A total of 30 runs for each experimental setting were conducted. 
The diversity measure of the swarm can be calculated as [10]:

$\operatorname{Diversity}(S(t))=\frac{1}{n_{S}} \sum_{i=1}^{n_{S}} \sqrt{\sum_{j=1}^{n_{x}}\left(x_{i j}(t)-\overline{x_{j}(t)}\right)^{2}}$

where $\mathrm{S}$ is the swarm, $\mathrm{n}_{\mathrm{s}}=|\mathrm{S}|$ is the swarm size, $\mathrm{n}_{\mathrm{x}}$ is the dimensionality of the problem, $x_{i j}$ is the $j^{\prime}$ th value of the $i^{\prime}$ th particle and $\overline{x_{j}(t)}$ is the average of the $\mathrm{j}$-th dimension over all particles, i.e. $\quad \overline{x_{j}(t)}=\frac{\sum_{i=1}^{n_{S}} x_{i j}(t)}{n_{S}}$

The results of the given benchmark problems for dimension 30 are shown in Table II in terms of mean best fitness, standard deviation, diversity, the improvement (\%), and t-values of proposed BMPSO algorithm in comparison with original PSO. In addition, we have tested the benchmark problems $f_{1}-f_{6}$ with the two more different dimensions 10 and 50; the corresponding results are given in Table III. Figures $1-6$ shows the performance curves of PSO and BMPSO algorithms. From the numerical results of Table II, we can see that the proposed algorithm perform better than the original PSO algorithm by a significant difference. The first test function $f_{1}$ is Rastringin function, which is a multimodal function. For this function, BMPSO gave a remarkable percentage of improvement of approximately $72 \%$ in comparison with PSO. For the function $f_{2}$, which is also a multimodal function, the proposed BMPSO algorithm performs much better than the original PSO algorithm. For the functions $f_{4}$ and $f_{10}$, the proposed BMPSO algorithm performs little better than PSO, in these test cases BMPSO algorithm gave approximately $4 \%$ improvement in comparison to original PSO. Likewise all the other test cases also we can see that there is a noticeable percentage of improvement in average mean value by using the proposed diversity based mutation algorithm. From the numerical results of Table III also, we can see that the proposed algorithm gave better results than PSO.

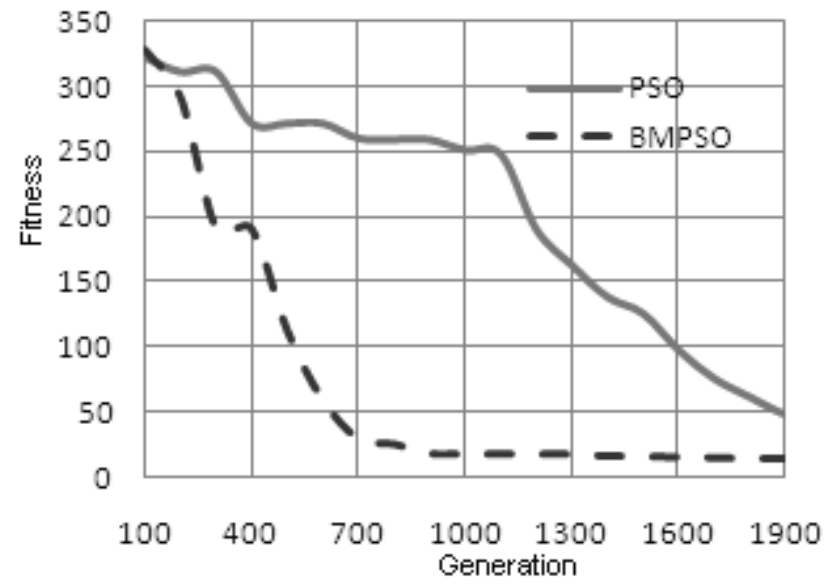

Figure 1. Performance curves of PSO and BMPSO for function $f_{1}$

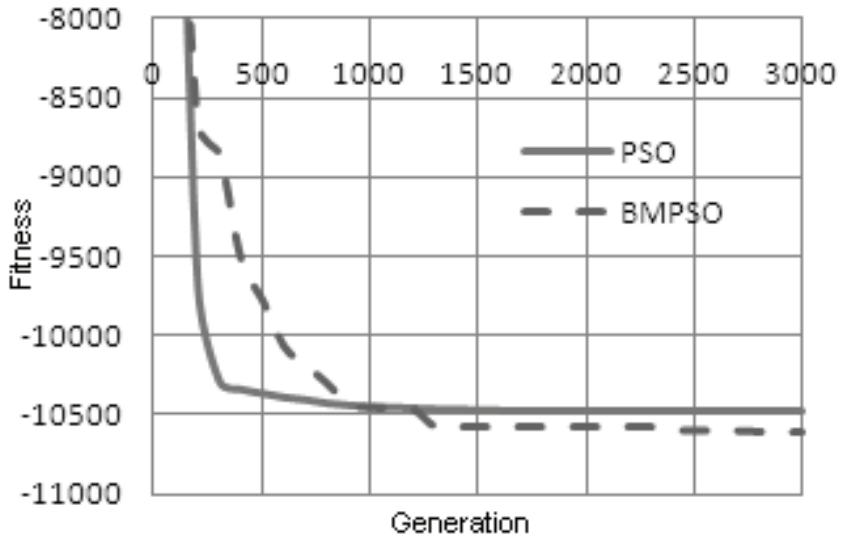

Figure 2. Performance curves of PSO and BMPSO for function $f_{4}$

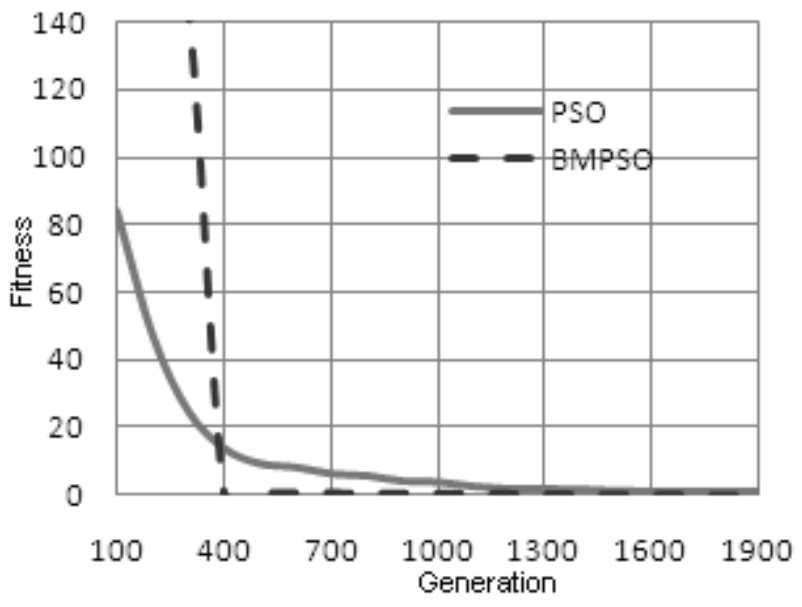

Figure 3. Performance curves of PSO and BMPSO for function $f_{5}$

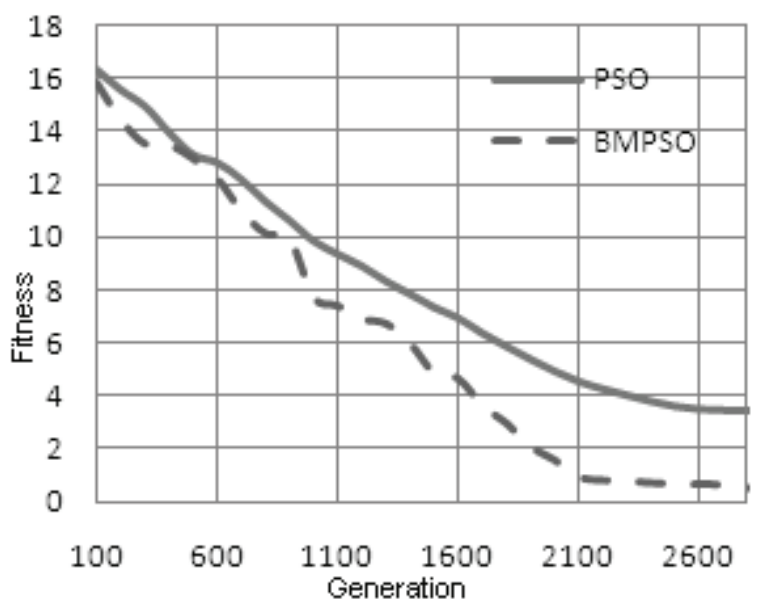

Figure 4. Performance curves of PSO and BMPSO for function $f_{6}$ 
TABLE I. NUMERICAL BENCHMARK PROBLEMS

\begin{tabular}{|l|l|l|l|}
\hline Function & Function Definition & Range & Optimum \\
\hline $\begin{array}{l}\text { Rastringin } \\
\text { Function }\end{array}$ & $f_{1}(x)=\sum_{i=1}^{n}\left(x_{i}{ }^{2}-10 \cos \left(2 \pi x_{i}\right)+10\right)$ & {$[-5.12,5.12]$} & 0 \\
\hline $\begin{array}{l}\text { Griewank } \\
\text { Function }\end{array}$ & $f_{2}(x)=\frac{1}{4000} \sum_{i=0}^{n-1} x_{i}{ }^{2}+\sum_{i=0}^{n-1} \cos \left(\frac{x_{i}}{\sqrt{i+1}}\right)+1$ & {$[-600,600]$} & 0 \\
\hline $\begin{array}{l}\text { Rosenbrock } \\
\text { Function }\end{array}$ & $f_{3}(x)=\sum_{i=0}^{n-1} 100\left(x_{i+1}-x_{i}{ }^{2}\right)^{2}+\left(x_{i}-1\right)^{2}$ & {$[-30,30]$} & 0 \\
\hline $\begin{array}{l}\text { Schwefel } \\
\text { Function }\end{array}$ & $f_{4}(x)=-\sum_{i=1}^{n} x_{i} \sin \left(\sqrt{\left|x_{i}\right|}\right)$ & {$[-500,500]$} & -12569.5 \\
\hline $\begin{array}{l}\text { Noisy Function } \\
\text { Ackley Function }\end{array}$ & $f_{5}(x)=\left(\sum_{i=0}^{n-1}(i+1) x_{i}{ }^{4}\right)+\operatorname{rand}[0,1]$ & {$[-1.28,1.28]$} & 0 \\
\hline $\begin{array}{l}\text { Schwefel } \\
\text { function } 1.2\end{array}$ & $f_{7}(x)=\sum_{i=0}^{n-1}\left(\sum_{j=0}^{i} x_{i}\right)^{2}$ & {$[-32,32]$} & 0 \\
\hline $\begin{array}{l}\text { Schwefel } \\
\text { function 2.21 }\end{array}$ & $f_{8}(x)=\max ^{2}\left|x_{i}\right|, 0 \leq i<n$ & {$\left[-10.2 \sqrt{\frac{1}{n} \sum_{i=1}^{n} x_{i}{ }^{2}}\right)-\exp \left(\frac{1}{n} \sum_{i=1}^{n} \cos \left(2 \pi x_{i}\right)\right)$} & 0 \\
\hline $\begin{array}{l}\text { Schwefel } \\
\text { function 2.22 }\end{array}$ & $f_{9}(x)=\sum_{i=0}^{n-1}\left|x_{i}\right|+\prod_{i=0}^{n-1}\left|x_{i}\right|$ & {$[-100,100]$} & 0 \\
\hline $\begin{array}{l}\text { Shaffer's } \\
\text { function 7 }\end{array}$ & $f_{10}(x)=\left(\sum_{i=1}^{n} x_{i}{ }^{2}\right)^{1 / 4}\left[\sin ^{2}\left(50\left(\sum_{i=1}^{n} x_{i}{ }^{2}\right)^{1 / 10}\right)+1.0\right]$ & {$[-10,10]$} & 0 \\
\hline
\end{tabular}

TABLE II. COMPARISON RESULTS OF PSO AND BMPSO IN TERMS OF AVERAGE FITNESS FUNCTION VALUE, STANDARD DEVIATION AND DIVERSITY

\begin{tabular}{|c|c|c|c|c|c|c|c|c|}
\hline \multirow{2}{*}{ Function } & \multicolumn{2}{|c|}{ Fitness Value } & \multicolumn{2}{|c|}{ Standard Deviation } & \multicolumn{2}{c|}{ Diversity } & \multicolumn{2}{c|}{$\begin{array}{c}\text { Improvement (\%) and } \\
\text { t-value of BMPSO } \\
\text { with PSO }\end{array}$} \\
\cline { 2 - 9 } & PSO & BMPSO & PSO & BMPSO & PSO & BMPSO & Improvement & t-value \\
\hline$f_{1}$ & 47.29223 & $\mathbf{1 3 . 3 4 4 4 5}$ & 11.06489 & $\mathbf{4 . 6 9 0}$ & 3.70371 & $3.01 \mathrm{e}-05$ & 71.78 & 15.47 \\
\hline$f_{2}$ & 0.0182 & $\mathbf{0 . 0 0 2 5 2 5}$ & 0.244025 & $\mathbf{0 . 0 0 1 5 8 9}$ & 33.1326 & 0.009598 & 86.12 & 0.35 \\
\hline$f_{3}$ & 316.4468 & $\mathbf{7 4 . 7 6 1 0 6}$ & 80.001 & $\mathbf{2 4 . 3 7 8 5 8}$ & 4.15842 & $3.14 \mathrm{e}-05$ & 76.37 & 15.82 \\
\hline$f_{4}$ & -6466.19 & $\mathbf{- 6 7 1 8 . 4 9}$ & $\mathbf{6 4 3 . 4 8 2 1}$ & 666.7723 & 0.42845 & 0.01666 & 3.9 & 1.49 \\
\hline$f_{5}$ & 0.617222 & $\mathbf{0 . 0 7 2 4 3 3}$ & 0.492993 & $\mathbf{0 . 2 1 4 9 8}$ & 0.547031 & 0.071049 & 88.26 & 5.54 \\
\hline$f_{6}$ & 1.70 & $\mathbf{0 . 0 7 7 4 6 1}$ & 0.4530 & $\mathbf{0 . 0 6 7 4 2}$ & 1.56783 & 0.60276 & 95.43 & 19.36 \\
\hline$f_{7}$ & 271.793 & $\mathbf{2 8 . 9 3 8}$ & 208.325 & $\mathbf{9 8 . 7 0 8 3}$ & 4.7239 & 0.10343 & 89.35 & 5.77 \\
\hline$f_{8}$ & 15.2228 & $\mathbf{9 . 9 6 4 1 4}$ & 3.652739 & $\mathbf{2 . 0 0 6 8 4}$ & 63.3639 & 6.60096 & 34.54 & 6.91 \\
\hline$f_{9}$ & 0.209776 & $\mathbf{0 . 1 6 9 5 5 1}$ & $\mathbf{0 . 0 7 2 4 0 7}$ & 0.625909 & 0.239009 & 0.02924 & 19.17 & 0.34 \\
\hline$f_{10}$ & 4.22028 & $\mathbf{4 . 1 0 4 4 7}$ & $\mathbf{0 . 4 1 6}$ & 0.460416 & 14.4341 & 0.806342 & 2.74 & 1.02 \\
\hline
\end{tabular}


TABLE III. COMPARISON RESULTS OF PSO AND BMPSO FOR FUNCTIONS $F_{1}-F_{6}$ WITH DIMENSION 10 AND 50

\begin{tabular}{|c|c|c|c|c|}
\hline Function & Dimension & PSO & BMPSO & $\begin{array}{c}\text { Improvement (\%) of BMPSO: } \\
\text { comparison with PSO }\end{array}$ \\
\hline \multirow{2}{*}{$f_{1}$} & 10 & 5.5572 & 0.012055 & 99.78307 \\
\cline { 2 - 5 } & 50 & 104.03725 & 27.889415 & 73.19286 \\
\hline \multirow{2}{*}{$f_{2}$} & 10 & 0.0919 & $3.726 \mathrm{e}-06$ & 99.99595 \\
\cline { 2 - 5 } & 50 & 0.014701 & 0.00415 & 71.77063 \\
\hline \multirow{2}{*}{$f_{3}$} & 10 & 96.1715 & 7.864022 & 91.82292 \\
\cline { 2 - 5 } & 50 & 533.64808 & 178.32484 & 66.58381 \\
\hline \multirow{2}{*}{$f_{4}$} & 10 & -2389.365 & -2764.422 & 15.6969 \\
\cline { 2 - 5 } & 50 & -10473.09 & -10605.52 & 1.26448 \\
\hline \multirow{2}{*}{$f_{5}$} & 10 & 0.502671 & 0.405912 & 19.24897 \\
\cline { 2 - 5 } & 50 & 0.788322 & 0.409282 & 48.08188 \\
\hline \multirow{2}{*}{$f_{6}$} & 10 & $6.965 \mathrm{e}-12$ & 0.004697 & - \\
\cline { 2 - 5 } & 50 & 3.43866 & 0.313801 & 90.87432 \\
\hline
\end{tabular}

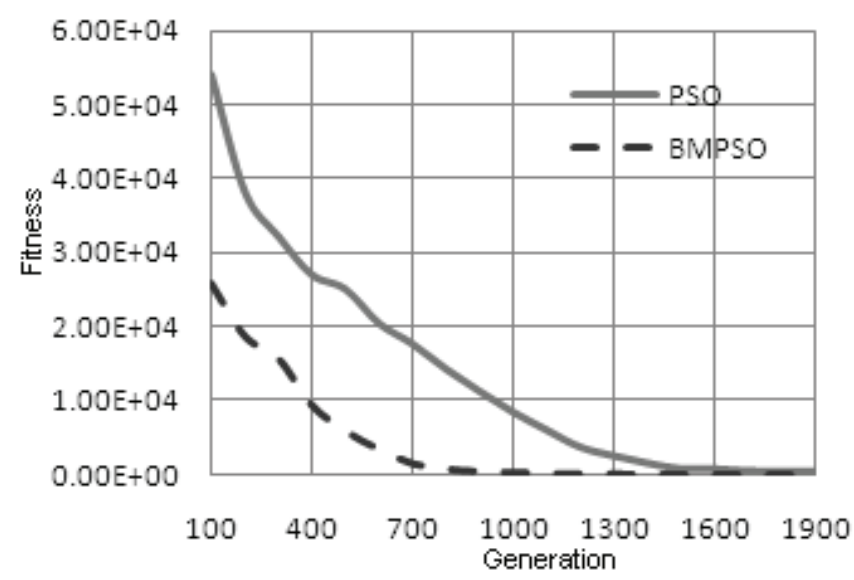

Figure 5. Performance curves of PSO and BMPSO for function $f_{7}$

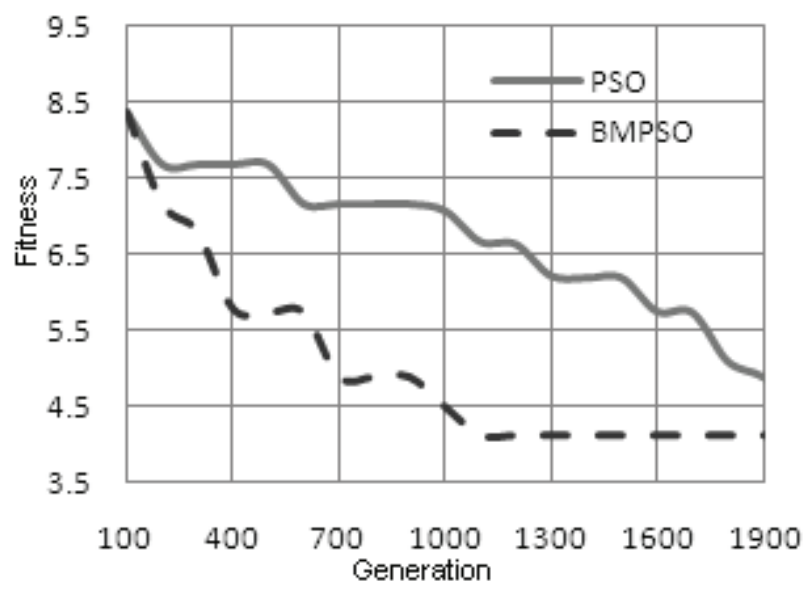

Figure 6. Performance curves of PSO and BMPSO for function $f_{10}$

\section{CONCLUSION}

In this paper, a simple and modified version of Particle Swarm Optimization named BMPSO has been proposed. The novelty of the present work is the use of diversity for activating the mutation. Another new feature is the use of a beta distributed mutation operator. The performance of BMPSO algorithm is tested with ten standard benchmark functions with various dimensions 10,30 and 50 . The empirical results show that the proposed BMPSO algorithm is efficient than the original PSO algorithm and is quite competent for solving problems of dimensions up to 50 . Thus, from the numerical results it is concluded that the BMPSO algorithm is simple and yet effective algorithm for solving different kind of optimization problems.

\section{REFERENCES}

[1] Kennedy, J. and Eberhart, R. C., "Particle Swarm Optimization", IEEE International Conference on Neural Networks (Perth, Australia), IEEE Service Center, Piscataway, NJ, Vol. IV, 1995, pp. 1942-1948.

[2] Robinson, J., Sinton, S. and Rahmat-Samii, Y., "Particle Swarm, Genetic Algorithm, and Their Hybrids: Optimization of a Profiled Corrugated Horn Antenna", In Proc. of the IEEE Antennas and Propagation Society International Symposium and URSI national radio Science meeting, Vol. 1, 2002, pp. $314-317$.

[3] Shi, Y. and Krohling, R. A., "Co-Evolutionary Particle Swarm Optimization to Solve Min-Max Problems", In Proc. of the IEEE Congress on Evolutionary Computation, Vol.2, 2002, pp. 1682 1687.

[4] Shi, X., Hao, J., Zhou, J. and Liang, Y., "Hybrid Evolutionary Algorithms Based on PSO and GA", In Proc. of the IEEE Congrss on Evolutionary Computation, Vol. 4, 2003, pp. 2393 - 2399.

[5] Zhang, W - J. and Xie, X - F., "DEPSO: Hybrid Particle Swarm with Differential Evolution Operator", In Proc. of IEEE Int. Conf. on Systems, Man \& Cybernetics, 2003, pp. 3816-3821. 
[6] Hao, Z-F., Guo, G-H. and Huang, H., "A Particle Swarm Optimization Algorithm with Differential Evolution", In Proc. of the $6^{\text {th }}$ Int. Conf. on Machine Learning and Cybernetics, 2007, pp. $1031-$ 1035.

[7] Yang, B., Chen, Y. and Zhao, Z., "A Hybrid Evolutionary Algorithm by Combination of PSO and GA for Unconstrained and Constrained optimization Problems", In Proc. of the IEEE Int. Conf. on Control and Automation, 2007, pp. $166-170$.

[8] $\mathrm{Hu}, \mathrm{X}$. , Eberhart, R. C. and Shi, Y., "Swarm Intelligence for Permutation Optimization: A Case Study on n-Queens problem", In Proc. of IEEE Swarm Intelligence Symposium, 2003, pp. 243 - 246.

[9] Juang, C - F., "A hybrid of genetic Algorithm and Particle Swarm Optimization for Recurrent Network Design", IEEE Trans. On Systems, Man, and Cybernetics - Part B: Cybernetics, Vol. 34(2), 2003, pp. $997-1006$.

[10] Engelbrecht, A. P., "Fundamentals of Computational Swarm Intelligence", England: John Wiley \& Sons Ltd, 2005.

[11] Wei, C., He, Z., Zheng, Y. and Pi, W., "Swarm Directions Embedded in Past Evolutionary Programming", In Proc. of IEEE Congress on Evolutionary Computation, Vol. 2, 2002, pp. $1278-1283$.

[12] Higashi, H. and Iba, H., "Particle Swarm Optimization with Gaussian Mutation", In Proc. of the IEEE Swarm Intelligence Symposium, 2003, pp. $72-79$.

[13] Secrest, B. R. and Lamont, G. B., "Visualizing Particle Swarm Optimization - Gaussian Particle Swarm Optimization", In Proceedings of the IEEE Swarm Intelligence Symposium, 2003, pp. $198-204$.
[14] Sriyanyong, P., "Solving Economic Dispatch Using Particle Swarm Optimization Combined with Gaussian Mutation", In Proc. of ECTICON, 2008, pp. $885-888$.

[15] Krohling, R. A., "Gaussian Particle Swarm with Jumps", In. Proc. of the IEEE Congress on Evolutionary Computation, Edinburgh, UK, 2005, pp. 1226-1231.

[16] Stacey, A., Jancic, M. and Grundy, I., "Particle Swarm Optimization with Mutation", In Proc. of the IEEE Congress on Evolutionary Computation, 2003, pp. $1425-1430$.

[17] Dong, D., Jie, J., Zeng, J. and Wang, M., "Chaos-Mutation-Based Particle Swarm Optimizer for Dynamic Environment", In Proc. of the $3^{\text {rd }}$ Int. Conf. on Intelligent System and Knowledge Engineering, 2008, pp. $1032-1037$.

[18] Yang, M., Huang, H. and Xiao, G., "A Novel Dynamic Particle Swarm Optimization Algorithm Based on Chaotic Mutation", Int. Workshop on Knowledge Discovery and Data Mining, 2009, pp. 656 -659 .

[19] Yue-lin, G., Xiao-hui, A. and Jun-min, L., "A Particle Swarm optimization Algorithm with Logarithm Decreasing Inertia Weigh and Chaos Mutation, In Proc. of Int. Conference on Computational Intelligence and Security, 2008, pp. $61-65$.

[20] Eberhart, R. C. and Shi, Y., "Particle Swarm Optimization: Developments, Applications and Resources", In Proc. of IEEE Congress of Evolutionary Computation, Vol. 1, 2001, pp. 27 - 30.

[21] Kennedy, J., "The Particle Swarm: Social Adaptation of Knowledge", In Proc. of the IEEE Int. Conf. on Evolutionary Computation, 1997, pp. $303-308$. 